\title{
A Parasite of Marine Rotifers: A New Lineage of Dinokaryotic Dinoflagellates (Dinophyceae)
}

\author{
Fernando Gómez ${ }^{1}$ and Alf Skovgaard ${ }^{2}$ \\ ${ }^{1}$ Laboratory of Plankton Systems, Oceanographic Institute, University of São Paulo, Praça do Oceanográfico 191, Cidade Universitária, \\ 05508-900 Butantã, SP, Brazil \\ ${ }^{2}$ Department of Veterinary Disease Biology, University of Copenhagen, Stigbøjlen 7, 1870 Frederiksberg C, Denmark
}

Correspondence should be addressed to Fernando Gómez; fernando.gomez@fitoplancton.com

Received 11 July 2015; Accepted 27 August 2015

Academic Editor: Gerardo R. Vasta

Copyright (C) 2015 F. Gómez and A. Skovgaard. This is an open access article distributed under the Creative Commons Attribution License, which permits unrestricted use, distribution, and reproduction in any medium, provided the original work is properly cited.

Dinoflagellate infections have been reported for different protistan and animal hosts. We report, for the first time, the association between a dinoflagellate parasite and a rotifer host, tentatively Synchaeta sp. (Rotifera), collected from the port of Valencia, NW Mediterranean Sea. The rotifer contained a sporangium with 100-200 thecate dinospores that develop synchronically through palintomic sporogenesis. This undescribed dinoflagellate forms a new and divergent fast-evolved lineage that branches among the dinokaryotic dinoflagellates.

\section{Introduction}

The alveolates (or Alveolata) are a major lineage of protists divided into three main phyla: ciliates, apicomplexans, and dinoflagellates. Molecular phylogeny has confirmed several morphologically identified parasitic lineages [perkinsids, ellobiopsids, euduboscquellids (Marine Alveolate Group I), and syndineans (Marine Alveolate Group II)] that branch between the apicomplexans (exclusively animal parasites) and "core" dinoflagellates (dinokaryotes) [1-3]. About 90 species of "core" dinoflagellates (dinokaryotes) and nearly all the basal dinoflagellates are parasites able to infect a broad array of protistan and animal hosts [4-7].

In studies based on molecular phylogeny, the genera Paulsenella Chatton, Amyloodinium E. Brown \& Hovasse, and Tintinnophagus D. W. Coats branch in the same clade and parasitize hosts of different phyla (diatoms, fishes, and ciliates, resp.) [8]. The parasites of copepod eggs Chytriodinium Cachon \& Cachon-Enjumet and Dissodinium G. A. Klebs are closely related and branch among free-living species $[9,10]$. The parasite of copepods Blastodinium Chatton, with chloroplast-containing and heterotrophic species, is not always a monophyletic group in SSU rDNA phylogenies [11]. The parasites Oodinium Chatton and Haplozoon Dogiel form independent lineages with no evident relation to other dinoflagellates [12]. In this study, we describe a new lineage of an undescribed parasitic dinoflagellate that largely diverged from other known dinoflagellates. This study also expands the range of hosts of parasitic dinoflagellates with the first example of infection in a rotifer.

\section{Materials and Methods}

2.1. Sampling and Microscopic Observations. The plankton sample was collected from the surface using a phytoplankton net (20 $\mu \mathrm{m}$ mesh size) on March 30, 2011, in the port of Valencia, NW Mediterranean Sea $\left(39^{\circ} 27^{\prime} 38.13^{\prime \prime} \mathrm{N}, 0^{\circ} 19^{\prime} 21.29^{\prime \prime}\right.$ $\mathrm{W}$, water column depth of $4 \mathrm{~m}$ ) by using a phytoplankton net $(20 \mu \mathrm{m}$ mesh size). The live, concentrated sample was examined in Utermöhl chamber at magnification of $\times 100$ with an inverted microscope (Nikon Eclipse T2000) and photographed with an Olympus DP71 digital camera. The infected host was photographed and then micropipetted with a fine capillary into a clean chamber and washed several times in a series of drops of $0.2 \mu \mathrm{m}$ filtered and sterilized seawater. After observation through microscopy, the sporangium containing the dinospores was broken and 
dinospores were placed in a $0.2 \mathrm{~mL}$ tube filled with a few drops of absolute ethanol.

2.2. PCR Amplification and Sequencing. The sample containing parasite dinospores in ethanol was kept at room temperature and in darkness until the molecular analysis could be performed. Prior to PCR, the sample tube was centrifuged and ethanol was evaporated by placing the tube overnight in a desiccator at room temperature. Then $30 \mu \mathrm{L}$ of sterile DNase-free water was added to the sample tube and the sample was sonicated through three 10-second pulses at an output setting of 1.0 [8] using a Virsonic 600 sonicator (SP Scientific, Gardiner, NY) equipped with a microtip. Ten microlitres of the crude cell lysate was used for polymerase chain reaction (PCR) amplification. SSU rDNA was amplified using the primers EukA and EukB [13]. PCR amplification was performed in a $25 \mu \mathrm{L}$ reaction volume containing 1.25 units of Biotaq polymerase (Bioline Reagents Limited, London, UK), buffer supplied with the polymerase, $\mathrm{MgCl}_{2}$ at $3.0 \mathrm{mM}$, dNTPs at $1.6 \mathrm{mM}$, and the forward and reverse primers at $1.0 \mathrm{mM}$. The PCR was run in a T100 Thermal Cycler (Bio-Rad Laboratories, Hercules, CA) under the following conditions: initial denaturation $\left(94^{\circ} \mathrm{C} / 2 \mathrm{~min}\right)$; 35 cycles of denaturation $\left(94^{\circ} \mathrm{C} / 15 \mathrm{~s}\right)$, annealing $\left(57^{\circ} \mathrm{C} / 30 \mathrm{~s}\right)$, and extension $\left(72^{\circ} \mathrm{C} / 2 \mathrm{~min}\right)$; final extension $\left(72^{\circ} \mathrm{C} / 7 \mathrm{~min}\right)$. PCR products were purified using Illustra GFX PCR DNA and Gel Purification Kit (GE Healthcare, Little Chalfont, UK) and sequenced bidirectionally with an $\mathrm{ABI} 3730 \mathrm{xl}$ sequencer (Macrogen Europe, Amsterdam, Netherlands) using the same primers as used for PCR and additional internal primers Ask12F and Ask2R [12]; ND2F and ND9R [14]; 528F and 1055R [15]; and 1209F [16]. Sequence reads were aligned and assembled using the software ChromasPro 1.75 (Technelysium, Brisbane, Australia). The newly generated sequence was deposited in DDBJ/EMBL/GenBank under accession number KT008058.

2.3. Phylogenetic Analyses. The analysis (Dinokaryota tree) comprised sequences for dinokaryotes most similar to the parasite of rotifers as identified through BLAST search (http://blast.ncbi.nlm.nih.gov/Blast.cgi; [17]). Furthermore, sequences of a wide selection of dinokaryotes and two syndinians were included, aiming at including species of all mutualist symbiotic and parasitic dinokaryote genera for which sequences were available. Two perkinsid sequences were used as outgroup. The final matrix contained 65 sequences.

Sequences were aligned using Clustal X v2.1 [18] and ambiguously aligned sites were removed using Gblocks [19] with parameters set for less stringent conditions (minimum number of sequences for a flanking position: 28; minimum length of a block: 5; allow gaps in half positions). Final alignments of the SSU rDNA sequences spanned over 1,716 positions. Bayesian phylogenetic trees were constructed with MrBayes v3.2 [20]. MrBayes settings for the best-fit model $(\mathrm{GTR}+\mathrm{I}+\mathrm{G})$ were selected by AIC in MrModeltest 2.3 [21]. Four simultaneous Monte Carlo Markov chains were run from random trees for a total of 2,000,000 generations in two parallel runs. A tree was sampled every 100 generations, and the first 2,000 trees (burn-in) were discarded before calculating posterior probabilities and constructing a Bayesian consensus tree.

\section{Results}

The host containing actively moving dinospores was observed to be immotile at the bottom of the settling chamber. The dimensions of the host were $135 \mu \mathrm{m}$ length and $50 \mu \mathrm{m}$ width (Figures $1(\mathrm{a})-1(\mathrm{~d})$ ). The head of the host supported a series of mobile filaments, interpreted as being a corona of cilia and bristles, which created water current into the host's mouth (see video in Supplementary Material available online at http://dx.doi.org/10.1155/2015/614609, http://youtu.be/WosjATyy1DE). In the caudal side, the organism showed a foot with one pointed toe and in the opposite side a spur or vestigial toe (Figures 1(a) and 1(c)). The morphology of the host was highly deformed by the parasite. However, the general appearance, the presence of the bristles, and a toe suggested that the host was a rotifer, tentatively identified as a small species of the genus Synchaeta Ehrenberg.

The sporangium was located inside at the level of the alimentary tube and protruded from the host. The shape of the sporangium was ellipsoidal ( $90 \mu \mathrm{m}$ long, $60 \mu \mathrm{m}$ wide). The number of dinospores ranged between 100 and 200 . We did not observe the dinospores forming chains. The infected host was placed into a clean chamber and during the manipulation the sporangium broke and the dinospores dispersed. We did not observe any trophocyte or other differentiated cells of the parasite; we only observed swarmers. All the dinospores showed similar degree of maturation that suggested a palintomic sporogenesis.

Dinospores were ellipsoidal with a conical epitheca with a convex contour that protruded over the cingulum and the apex was round. The epitheca was slightly larger in size than the hemispherical hypotheca (Figures 1(e)$1(j))$. The cingulum was slightly postmedian and deep. The dinospores were $11 \mu \mathrm{m}$ in length and $7 \mu \mathrm{m}$ in width at the cingulum level. The cells showed refringent inclusions. The general appearance resembled an elongate cell of Heterocapsa pygmaea A.R. Loebl., R.J. Schmidt \& J.L. Sherley. Each dinospore possessed two dissimilar flagella, and they moved actively inside the sporangium and from the time when they were released (see video in Supplementary Material, http://youtu.be/WosjATyylDE).

An almost complete SSU rDNA sequence (1,721 base pairs) of the dinospores was obtained. A BLAST search was conducted on the new sequences to find related sequences in the GenBank database. However, similarities were low in all cases (maximum 82\%). We first studied the phylogenetic position in a SSU rDNA phylogenetic tree with diverse representatives of the alveolate lineages that unequivocally placed this undescribed parasite within the dinokaryotic lineage (data not shown). Then, we studied the phylogenetic position using a dataset that included sequences of other parasitic dinoflagellates and a diverse representation of the dinokaryotic lineages (Figure 2). In the Bayesian consensus tree, the SSU rDNA phylogeny revealed that the newly 


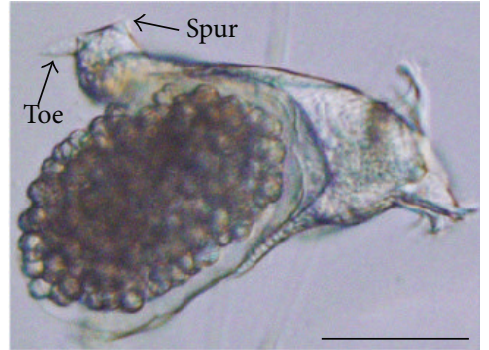

(a)

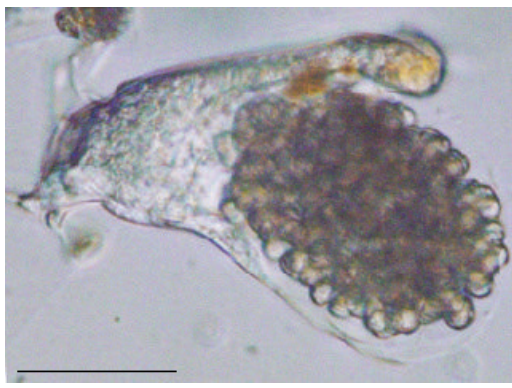

(d)

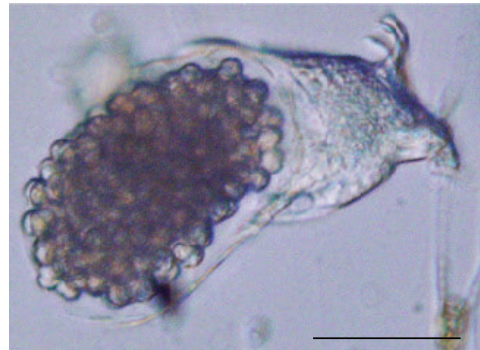

(b)

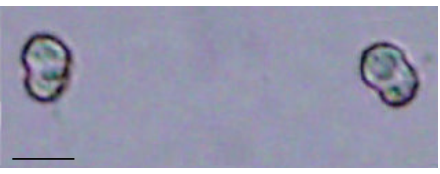

(e)

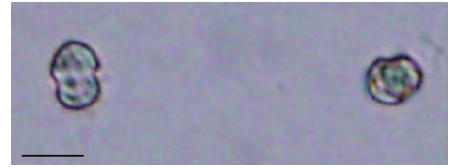

(f)

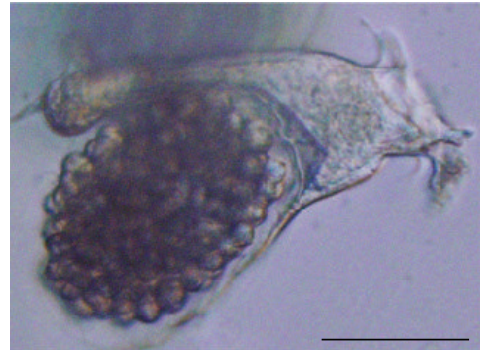

(c)

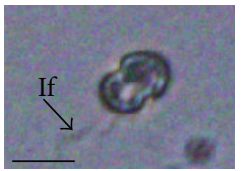

(g)

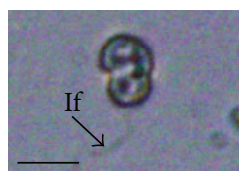

(h)

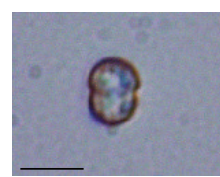

(i)

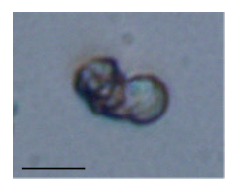

(j)

FIGURE 1: Light microscopy pictures of an undescribed dinokaryotic parasite of a rotifer, tentatively Synchaeta. (a)-(d) Infected host. (e)(j) Recently released dinospores. lf: longitudinal flagellum. See video in Supplementary Material, http://youtu.be/WosjATyylDE . Scale bars: (a)-(d) $50 \mu \mathrm{m}$; (e)-(j) $10 \mu \mathrm{m}$.

sequenced species formed a distinct lineage among the dinokaryotic dinoflagellates. However, it was not possible to find any close genetically characterized relatives of this parasite.

\section{Discussion}

Parasitic dinoflagellates have been reported in almost all the pelagic metazoan phyla [4-6]. Rotifers are largely represented in freshwater environments, and only about 14\% (254 taxa) are marine species [22]. Many rotifer species live in symbiosis, including true parasites harming their hosts [23]. On the other hand, freshwater rotifers are commonly infected by parasitic fungi [24]. However, to the best of our knowledge there are no records of infection by dinoflagellates.

The general appearance of the rotifer host is highly deformed by the mature sporangium. The host shows a resemblance to members of Synchaeta, a common genus in the coastal waters of the NW Mediterranean Sea [25]. The length of the host (135 $\mu \mathrm{m}$ long) agrees with the range of Synchaeta neapolitana Rousselet or S. cecilia Rousselet, both species characterized by one reduced toe [25]. The caudal end of the host, with a one pointed toe and a small lateral and oblique spur, is closer to S. neapolitana (Figures 1(a) and 1(c)).

The parasite developed in a sporangium that protruded from the rotifer body at the level of the alimentary tube. This suggests that the dinospore was ingested and developed in the alimentary tube or body cavity of the rotifer. The lack of records of dinoflagellates infecting rotifers could be due to the marine rotifers having received less attention as compared to their freshwater counterparts and/or because the earlier stages of infections of these endoparasites are mistaken with the gut contents or the vitellarium of the rotifer. The detection of the parasite is easier when the sporangium protrudes from the host.

This parasite of rotifers shows a superficial resemblance to Chytriodinium [26]. The latter produces a spherical sporangium that develops outside the host. In contrast, the sporangium of the parasite of rotifers is ellipsoidal and developed inside the host. The dinospores of Chytriodinium are unarmored and they formed a chain until the membrane of the sporangium is broken. The rigid contour of the dinospores suggests that this parasite of rotifers is a thecate form. We did not observe a chain of dinospores. However, we cannot rule out that at this developmental stage the dinospores were already separated. Both Chytriodinium and the parasite of rotifers seem to share a synchronic division by palintomic sporogenesis. This parasite of rotifers, as well as Haplozoon and Oodinium, is not related to other known dinoflagellates in the SSU rDNA phylogenies. Similarly to the parasite of rotifers, the phylogenetic position of Haplozoon and Oodinium is characterized by long branches. They all represent fast-evolved dinokaryotes without any close known relatives (Figure 2, [12]).

The proportion of parasitic species among the core dinoflagellates is low (3\%) and the percentage of parasitic dinoflagellates for which at least one DNA sequence is available is very low $(7 \%,[7,27])$. This is very likely due to difficulties in carrying out morphological studies with the small and actively moving dinospores. Parasites, especially the endoparasites, are only easily detectable at the last stage of the infection, which is an only short period in the life cycle 


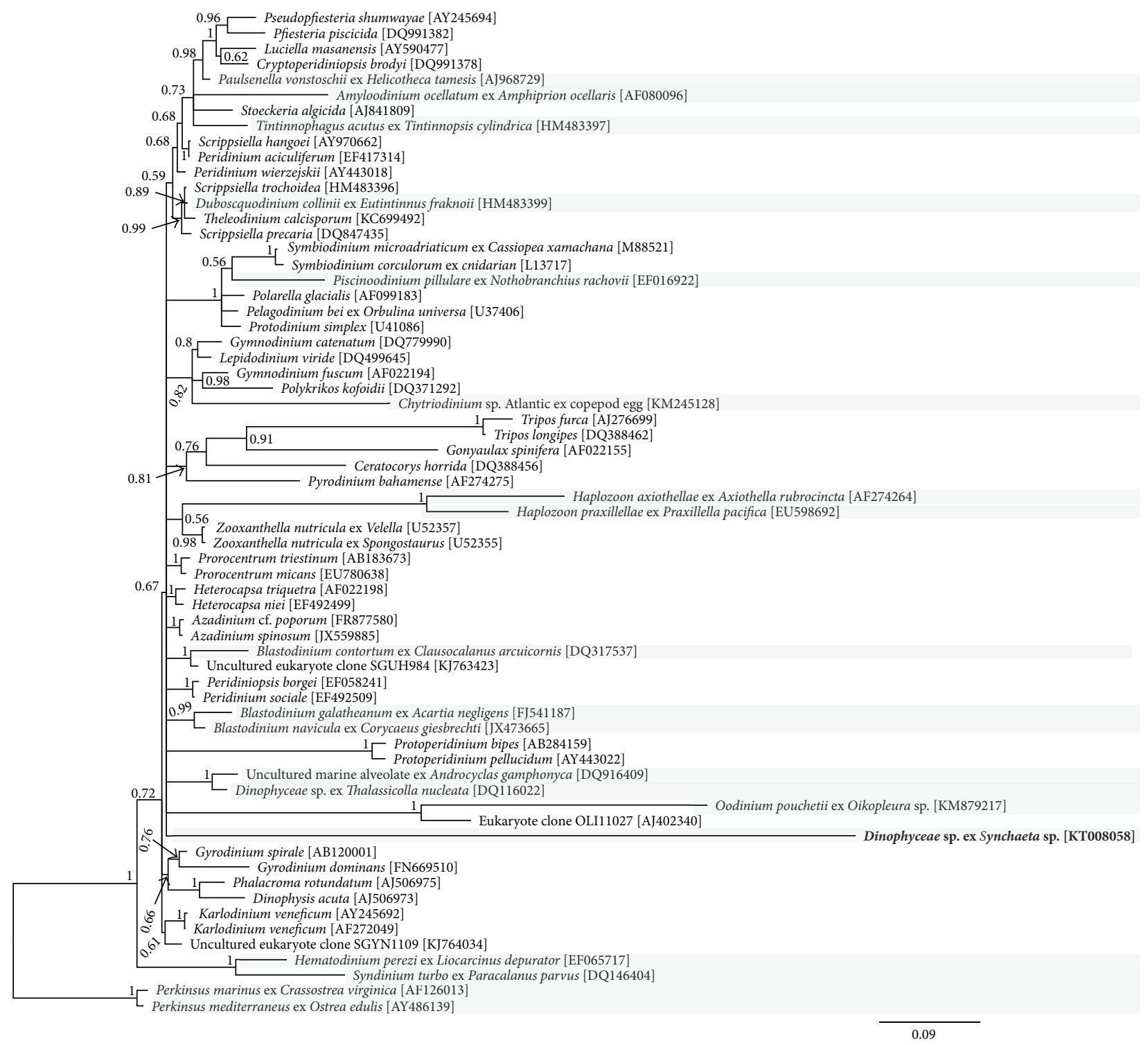

FIGURE 2: Phylogenetic tree of the dinoflagellates based on phylogenetic analysis of SSU rDNA sequences using Bayesian inference, based on 1,716 aligned positions. Perkinsozoa is used as outgroup. Parasitic taxa are highlighted. The species newly sequenced in this study are in bold. Posterior probabilities are given at nodes. The scale bar represents the number of substitutions per site.

of the parasite. This study constitutes the first record of a parasitic dinoflagellate infecting a rotifer and suggests a new lineage within the "core" dinoflagellates.

\section{Conflict of Interests}

The authors declare that there is no conflict of interests regarding the publication of this paper.

\section{Acknowledgments}

Fernando Gómez was supported by the Brazilian Conselho Nacional de Desenvolvimento Científico e Tecnológico
(Grant no. BJT 370646/2013-14). Alf Skovgaard was supported through the project IMPAQ, Improvement of Aquaculture High Quality Fish Fry Production, funded by the Danish Council for Strategic Research (Grant no. 10093522).

\section{References}

[1] A. Skovgaard, R. Massana, V. Balagué, and E. Saiz, "Phylogenetic position of the copepod-infesting parasite Syndinium turbo (Dinoflagellata, Syndinea)," Protist, vol. 156, no. 4, pp. 413423, 2005.

[2] A. Harada, S. Ohtsuka, and T. Horiguchi, "Species of the parasitic genus Duboscquella are members of the enigmatic Marine Alveolate Group I," Protist, vol. 158, no. 3, pp. 337-347, 2007. 
[3] F. Gómez, P. López-García, A. Nowaczyk, and D. Moreira, "The crustacean parasites Ellobiopsis Caullery, 1910 and Thalassomyces Niezabitowski, 1913 form a monophyletic divergent clade within the Alveolata," Systematic Parasitology, vol. 74, no. 1, pp. 65-74, 2009.

[4] J. Cachon and M. Cachon, "Parasitic dinoflagellates," in The Biology of Dinoflagellates, F. J. R. Taylor, Ed., pp. 571-610, Blackwell Publishing, Oxford, UK, 1987.

[5] D. W. Coats, "Parasitic life styles of marine dinoflagellates," Journal of Eukaryotic Microbiology, vol. 46, no. 4, pp. 402-409, 1999.

[6] S. Ohtsuka, K. Nagasawa, and K. Gejima, "Review of parasites of marine zooplankton," Bulletin of the Plankton Society of Japan, vol. 47, no. 1, pp. 1-16, 2000.

[7] F. Gómez, "A quantitative review of the lifestyle, habitat and trophic diversity of dinoflagellates (Dinoflagellata, Alveolata)," Systematics and Biodiversity, vol. 10, no. 3, pp. 267-275, 2012.

[8] D. W. Coats, S. Kim, T. R. Bachvaroff, S. M. Handy, and C. F. Delwiche, "Tintinnophagus acutus n. g., n. sp. (Phylum Dinoflagellata), an ectoparasite of the ciliate Tintinnopsis cylindrica Daday 1887, and its relationship to Duboscquodinium collini Grassé 1952," Journal of Eukaryotic Microbiology, vol. 57, no. 6, pp. 468-482, 2010.

[9] K.-Y. Kim, M. Iwataki, and C.-H. Kim, "Molecular phylogenetic affiliations of Dissodinium pseudolunula, Pheopolykrikos hartmannii, Polykrikos cf. schwartzii and Polykrikos kofoidii to Gymnodinium sensu stricto species (Dinophyceae)," Phycological Research, vol. 56, no. 2, pp. 89-92, 2008.

[10] F. Gómez and A. Skovgaard, "Molecular phylogeny of the parasitic dinoflagellate Chytriodinium within the Gymnodinium clade (Gymnodiniales, Dinophyceae)," Journal of Eukaryotic Microbiology, vol. 62, no. 3, pp. 422-425, 2015.

[11] A. Skovgaard, S. A. Karpov, and L. Guillou, "The parasitic dinoflagellates Blastodinium spp. inhabiting the gut of marine, planktonic copepods: morphology, ecology, and unrecognized species diversity," Frontiers in Microbiology, vol. 3, article 305, 2012.

[12] F. Gómez and A. Skovgaard, "The molecular phylogeny of the type-species of Oodinium Chatton, 1912 (Dinoflagellata: Oodiniaceae), a highly divergent parasitic dinoflagellate with non-dinokaryotic characters," Systematic Parasitology, vol. 90, no. 2, pp. 125-135, 2015.

[13] L. Medlin, H. J. Elwood, S. Stickel, and M. L. Sogin, "The characterization of enzymatically amplified eukaryotic 16S-like rRNA-coding regions," Gene, vol. 71, no. 2, pp. 491-499, 1988.

[14] F. Ekelund, N. Daugbjerg, and L. Fredslund, "Phylogeny of Heteromita, Cercomonas and Thaumatomonas based on SSU rDNA sequences, including the description of Neocercomonas jutlandica sp. nov., gen. nov., European Journal of Protistology, vol. 40, no. 2, pp. 119-135, 2004.

[15] H. J. Elwood, G. J. Olsen, and M. L. Sogin, “The small-subunit ribosomal RNA gene sequences from the hypotrichous ciliates Oxytricha nova and Stylonychia pustulata," Molecular Biology and Evolution, vol. 2, no. 5, pp. 399-410, 1985.

[16] S. J. Giovannoni, E. F. DeLong, G. J. Olsen, and N. R. Pace, "Phylogenetic group-specific oligodeoxynucleotide probes for identification of single microbial cells," Journal of Bacteriology, vol. 170, no. 2, pp. 720-726, 1988.

[17] S. F. Altschul, T. L. Madden, A. A. Schäffer et al., "Gapped BLAST and PSI-BLAST: a new generation of protein database search programs," Nucleic Acids Research, vol. 25, no. 17, pp. 3389-3402, 1997.
[18] M. A. Larkin, G. Blackshields, N. P. Brown et al., "Clustal W and clustal X version 2.0," Bioinformatics, vol. 23, pp. 2947-2948, 2007.

[19] J. Castresana, "Selection of conserved blocks from multiple alignments for their use in phylogenetic analysis," Molecular Biology and Evolution, vol. 17, no. 4, pp. 540-552, 2000.

[20] J. P. Huelsenbeck and F. Ronquist, "MrBAYES: bayesian inference of phylogenetic trees," Bioinformatics, vol. 17, no. 8, pp. 754-755, 2001.

[21] J. A. A. Nylander, "MrModeltest v2," 2004, https://www.abc .se/ nylander/mrmodeltest $2 /$ mrmodeltest $2 . h t m l$.

[22] D. Fontaneto, W. H. De Smet, and C. Ricci, "Rotifers in saltwater environments, re-evaluation of an inconspicuous taxon," Journal of the Marine Biological Association of the United Kingdom, vol. 86, no. 4, pp. 623-656, 2006.

[23] L. May, "Epizoic and parasitic rotifers," Hydrobiologia, vol. 186187, no. 1, pp. 59-67, 1989.

[24] C. G. Wilson and P. W. Sherman, "Anciently asexual bdelloid rotifers escape lethal fungal parasites by drying up and blowing away," Science, vol. 327, no. 5965, pp. 574-576, 2010.

[25] C. Rougier, R. Pourriot, and T. Lam-Hoai, “The genus Synchaeta (rotifers) in a north-western Mediterranean coastal lagoon (Etang de Thau, France): taxonomical and ecological remarks," Hydrobiologia, vol. 436, pp. 105-117, 2000.

[26] F. Gómez, D. Moreira, and P. López-García, "Life cycle and molecular phylogeny of the dinoflagellates Chytriodinium and Dissodinium, ectoparasites of copepod eggs," European Journal of Protistology, vol. 45, no. 4, pp. 260-270, 2009.

[27] F. Gómez, "Problematic biases in the availability of molecular markers in protists: the example of the dinoflagellates," Acta Protozoologica, vol. 53, no. 1, pp. 63-75, 2014. 

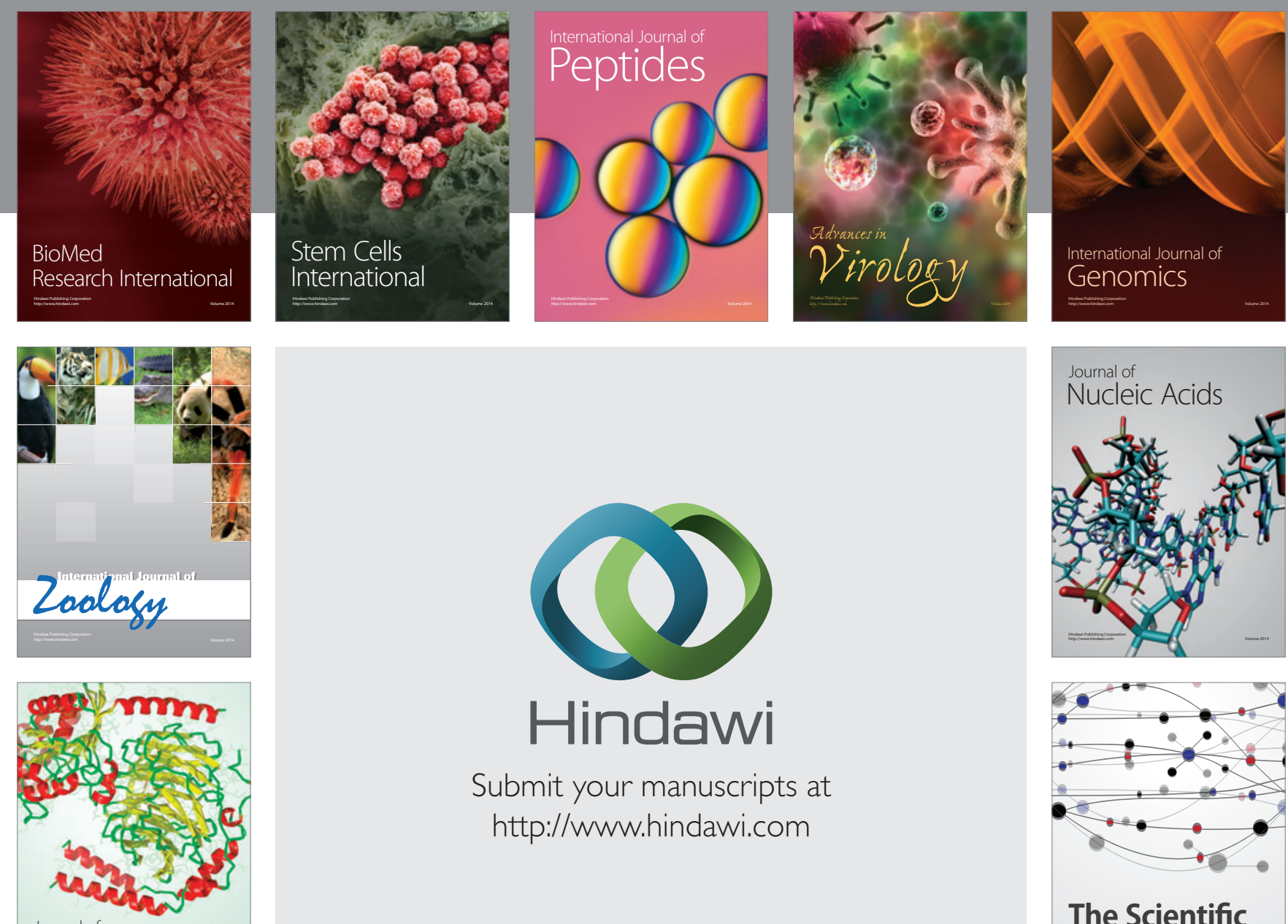

Submit your manuscripts at

http://www.hindawi.com

Journal of
Signal Transduction
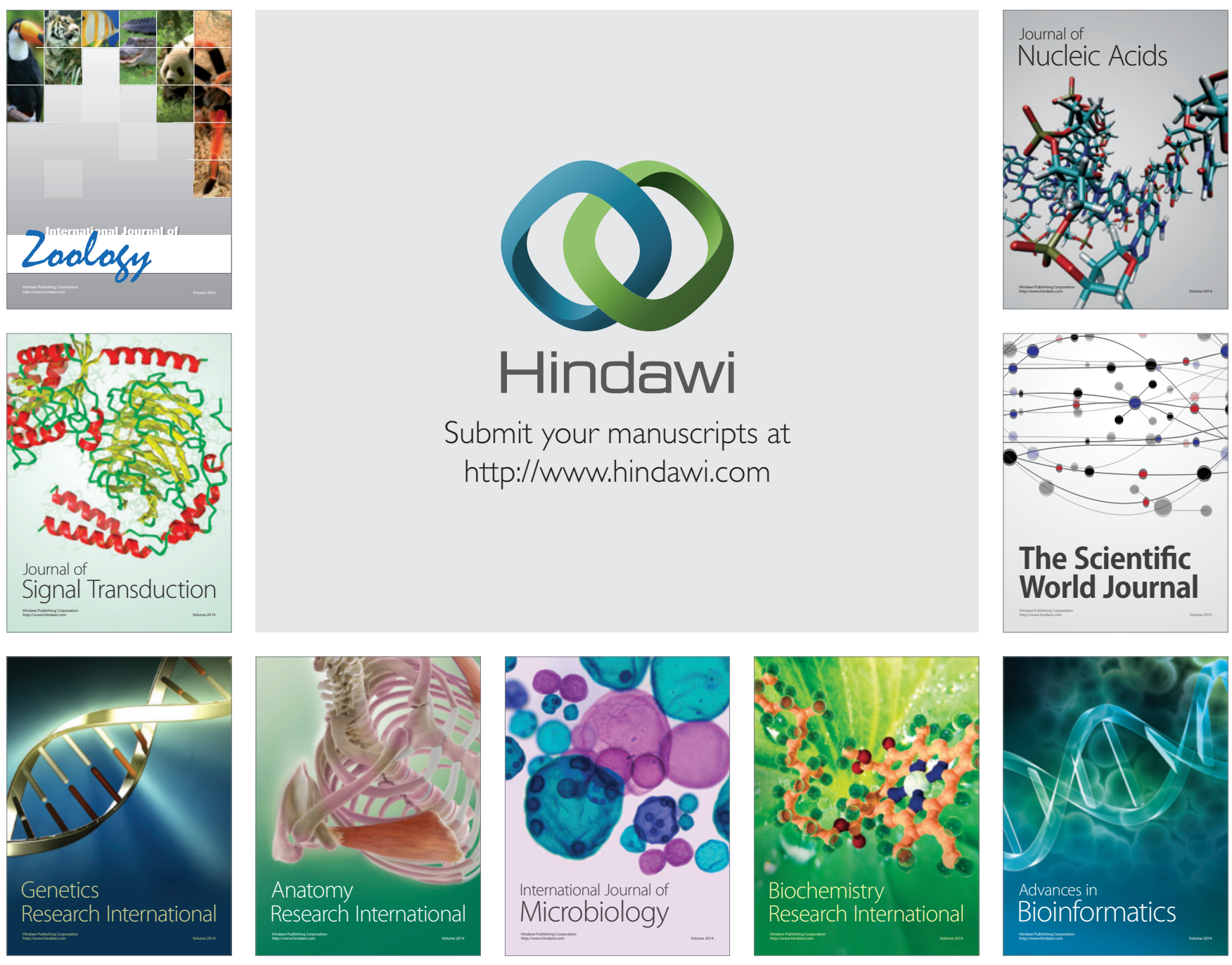

The Scientific World Journal
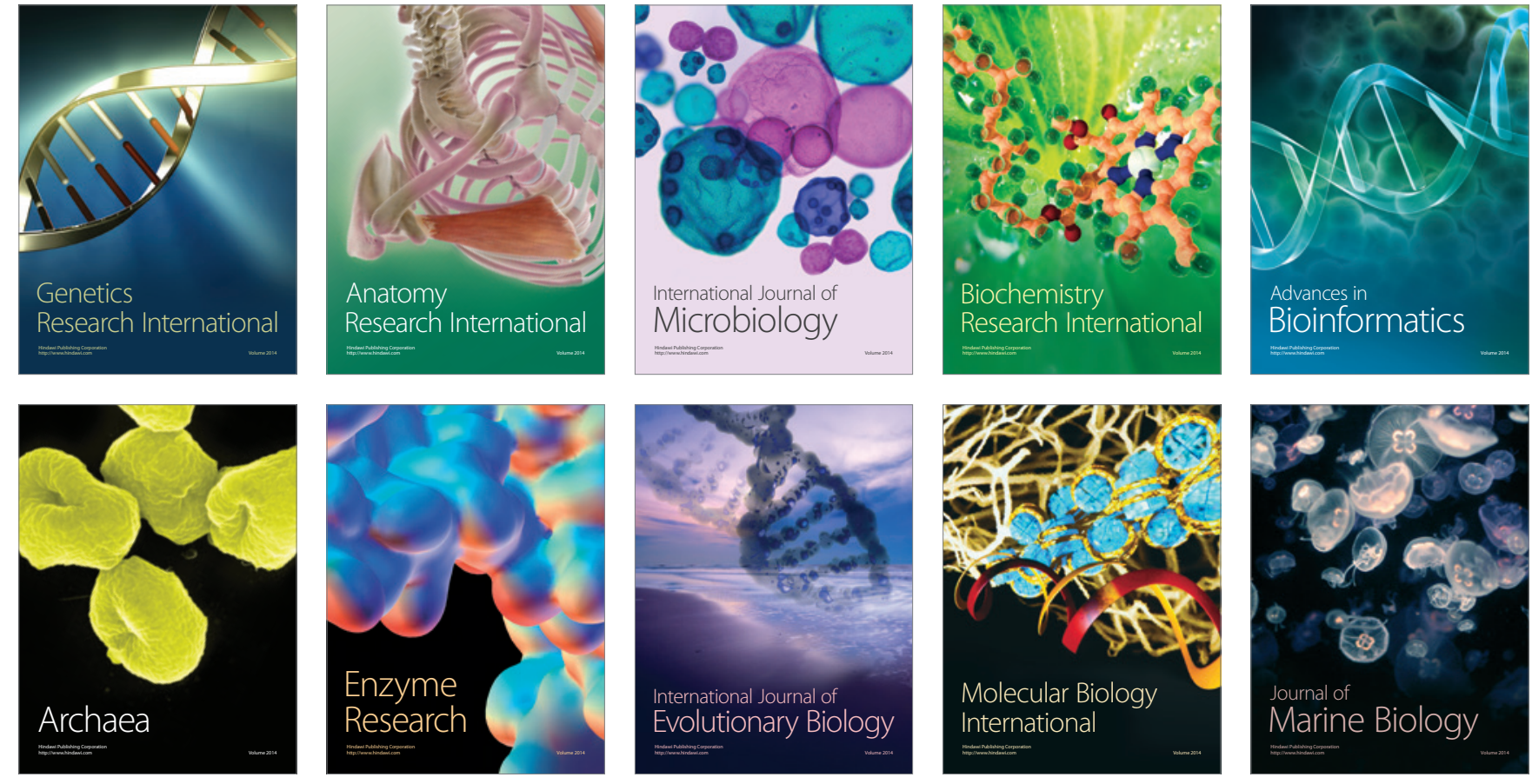